\title{
New Model Construction of Enterprise Information Resource Management under e-Commerce
}

\author{
Lifang Song $\mathbb{D}^{1}$ and Zichao Zhao ${ }^{2}$ \\ ${ }^{1}$ Labor Union Renming University of China, Beijing 100872, China \\ ${ }^{2}$ Financial School, Renmin University of China, Beijing 100872, China \\ Correspondence should be addressed to Lifang Song; slifang@ruc.edu.cn
}

Received 30 July 2021; Revised 1 September 2021; Accepted 7 September 2021; Published 25 September 2021

Academic Editor: Sang-Bing Tsai

Copyright (c) 2021 Lifang Song and Zichao Zhao. This is an open access article distributed under the Creative Commons Attribution License, which permits unrestricted use, distribution, and reproduction in any medium, provided the original work is properly cited.

\begin{abstract}
Enterprise information resource management is one of the important branches in the field of information resource management, and it is also the focus and hot spot of information resource management academic research. The arrival of e-commerce era brings opportunities and challenges to enterprise information resource management, which will enter a new stage. Under the environment of e-commerce, the organic combination of enterprise resource planning, supply chain management, customer relationship management, and e-commerce will become an urgent and inevitable choice for enterprises. The purpose of this paper is to establish an innovative model of enterprise information resource management in the e-commerce environment. Combined with the enterprise information resource management in the e-commerce environment, this paper studies the model framework, theoretical system, and technical implementation method of enterprise information resource management. According to the research status of enterprise information resource management, this paper analyzes the enterprise information resource management under the e-commerce environment and adopts the experimental method of simulating the information resource management environment. The idea of "three networks" + "three systems" is put forward. The experimental results show that in 2019, the investment of e-commerce enterprises in hardware products decreased by $3.3 \%$ and the proportion of software and information services increased by $2 \%$ and $1.3 \%$, respectively. The enterprise information resource management model constructed in this paper has very important practical significance.
\end{abstract}

\section{Introduction}

In the current market environment of the network economy, information is a very important resource, and it has also become one of the important factors of productivity [1]. Enterprise information resource management should pay attention to the research of technology application, avoid duplication of information construction and scattered waste, reduce the loss of information in the way of information collection, and avoid redundancy when using information [2]. The core task of enterprise information resource management is to improve the ability of enterprise to collect, process, and apply information resources, realize the promotion of information resources, enhance the ability of enterprise production and operation value creation, and maximize the investment of information construction. In the information age, building a new model of enterprise information resource management is one of the most effective means to enhance the core competitiveness of enterprises, and it is also the core issue of enterprise information resource organization and management. Nowadays, the rapid development of digital, network, and other technologies has led to the rapid increase in the renewal of various industries [3]. Together with the development of world-free trade and global integration, the survival and competitive environment of modern enterprises are also changing. New enterprises in each industry are becoming more and more; it has led to vicious competition among enterprises for making money and has destroyed the living environment of the entire industry [4]. 
The information based on the three traditional resources of land, capital, and labor will become the strategic resources of enterprises during the fourth World War. The importance of information as a factor of production is increasing day by day. Information resource management based on information resource has become an important condition for enterprises to improve their competitiveness. No matter in the production industry or service industry, the basic activities of enterprises can be expressed by value chain. The author thinks that the enterprise information resource management can innovate the means of information resource management from the perspective of value chain and construct the value chain management mode of information resource management. Through the e-commerce data exchange center, consumers who want to buy a certain product can timely compare the quotations and product performance of numerous suppliers around the world. Buyers often have access to suppliers' information about their products, services, and offers. Their buying behavior has become very effective. At the same time, the industry oversupply, product and process innovation, a lot of information that can be seen everywhere, smart consumers, and other factors (such as fast pace of life, improved production efficiency, and quality) make any commodity quickly become common consumer goods, which inevitably leads to the enterprise involuntarily into the price war, and the declining trend of profits is increasingly obvious. It is very difficult for manufacturers to create a unique product image in the eyes of consumers. Therefore, if an enterprise wants to lead the industry and seize opportunities in the current social competition [5], the key is to have a large amount of information resources and to manage and use the information resources it owns, that is, to manage the large amount of information collected and reasonable use different types of information [6]. By discovering the changes of customers' demands, the enterprise puts forward and implements the strategy of meeting customers' new demands in time and constantly creates cost value for customers. To a great extent, the success of enterprise e-commerce activities depends on the level and quality of information resource management. The model of information resource value chain management not only emphasizes information technology but also emphasizes the coordination and management of all departments, objectively examines the current situation of enterprise development, and correctly guides the future development direction of enterprise.

More and more users develop or integrate cross functional, enterprise, or infrastructure systems into an organization, with little involvement of senior management or central information technology (it) departments. Chua, Cecil Eng Huang suggested that the bottom-up enterprise information system will reshape the central IT, making it more involved in governance, coordination and strategy formulation, and less involved in actual implementation and maintenance. Effective management of bottom-up enterprise information system needs effective distributed leadership, including establishing power balance, fuzzy roles, trust and trusteeship between central IT departments and functional departments. Lyytinen, Kalle analyzed how the ERP system has been successfully implemented in two recently established independent university groups. For political and functional reasons, ERP is used to replace some traditional student management systems. New university project consultants and management believe it is successful, while users are marginalized (black box), using traditional methods, such as shadow system and shift, to pick up fragments of an incomplete system. By using the process method and the theory of participating in network, this paper interprets the relevant social technology events, reveals how the three participating networks of management, project team, and management users collide and affect the implementation effect, and how the management and project network establish ERP as a reliable alliance. These users are marginalized when they join the network.

Based on the analysis of enterprise information resource management in e-commerce environment, the idea of "three networks" + "three systems" enterprise three-dimensional information resource management is put forward, and the definition of enterprise three-dimensional information resource management is given. In addition, this paper also analyzes the three-dimensional enterprise information resource management platform Internet, intranet, extranet, and management system ERP, SCM, and CRM system management network and analyzes the differences between them from the management content and implementation of the key issues. The simulation test is carried out for the specific information resource management. The simulation information resource management environment and the method of statistical test information are used. The experimental results show that in 2019 , the investment of e-commerce enterprises in hardware products decreased by $3.3 \%$, and the proportion of software and information services increased by $2 \%$ and $1.3 \%$.

\section{Proposed Method}

2.1. Information Resource Management. The information generated by enterprises in related enterprises such as operation, technology research and development, production, management, and marketing is collectively referred to as enterprise information resources [7]. These corporate information resources can greatly improve the development of the company, leading other companies in the same industry [8]. It is also an enterprise information technology application, network integration, business application system, network portal system, e-commerce system, and related hardware equipment [9]. These types of software have different functions and can be perfectly integrated. In addition, enterprise information resources technical personnel and information resource users, the former is the collection and processing of resource information, while the latter is the main operator of resource information and a collection of related information work resources [10].

The task of enterprise information resource management is to effectively collect, acquire and process information inside and outside the enterprise, maximize the quality, availability, and value of enterprise information resources, and make all parts of the enterprise share these information 
resources. Information resource management is based on a certain organizational structure or organizational model of information resource management. The research of enterprise information resource management can be divided into three categories: the first category is oriented to specific business scenarios and industry fields; the second category is industry oriented; the third category is characterized by technology [11]. Among them, the first category can be used in banking, finance, Internet, and other industries; the second category can be used in education, sports, and other industries; and the third category can be used in related technology industries, such as machinery and manufacturing [12]. Research on specific business scenarios and industries can be divided into application research, which needs to rely on specific information resources for analysis and design.

\subsection{Enterprise Information Resource Management Model} Based on e-Commerce. e-Commerce will change the relationship between enterprises and consumers and will bring new value opportunities and challenges [13]. Therefore, we can start from the perspective of corporate management and use different models according to the company's strategic positioning, scientific management foundation, and business management process [14]. Different e-commerce models will bring different values and requirements to corporate management [15].

2.2.1. Utility Value of Enterprise Information Resources. The value of enterprise information resources lies in the improvement of production and decision-making efficiency, as well as the dissemination of information, the elimination of uncertainty and the effectiveness of production. The value characteristics and laws of enterprise information resources can be described from the audience and richness:

$$
V_{\text {inf }}=/ f(N, H) \text {. }
$$

Among them, $N$ is the audience of enterprise information resources and $H$ is the richness of enterprise information resources.

Value $v_{\text {inf }}$ is a combination of two dependent variables $N$ and $h$, both of which are positively correlated. In order to improve the utility value of information resources, $v_{\text {inf }}$, it is necessary to improve the audience and richness of information resources.

\subsubsection{Architecture Design of Collaborative Management} Information Resources. The brittleness of enterprise information resource management consists of brittleness factors, brittleness events and brittleness results, which constitute the whole brittleness prototype, namely, subsystem brittleness risk, organization brittleness risk, and associated brittleness risk. Because brittleness is not only the potential negative factor of enterprise information resource management, but also the resistance factor that affects the utility value of enterprise information resource management. Before analyzing the vulnerability of enterprise information resource management, the framework of enterprise information resource management is set as $S$.

For each subsystem of $S, S_{i}(i=1,2, \ldots, 6)$, with $S_{i}=S_{i}=\left(S_{i j}\right)(i=l, 2, \ldots 6, j=1,2, \ldots, m)$, where $S_{i j}$ is the brittleness factor describing the brittleness characteristics of the subsystem. By classifying the brittleness factors of $S_{i}$, we can divide $\left(S_{i j}\right)$ into $\mathrm{Ni}$ group. Among them, $N_{i}=\{1,2\}$, including corporate headquarters, branches, and their branches. There are $n_{1}+n_{2}=m$, where $=n_{k}(k=1,2)$ is the brittle factor of subsystem $S_{i}$ belonging to class $k$ in $N_{i}$. The brittleness entropy of subsystem $S_{i}$ is defined as follows:

$$
C\left(S_{i}\right)=-\frac{n_{1}}{m} \ln \frac{n_{1}}{m}-\frac{n_{2}}{m} \ln \frac{n_{2}}{m} .
$$

The joint brittleness entropy of $S_{i}$ and $S_{j}$ subsystem is defined as

$C(S \cup S)=-\frac{n_{11}}{m} \ln \frac{n_{11}}{m}-\frac{n_{12}}{m} \ln \frac{n_{12}}{m}-\frac{n_{21}}{m} \ln \frac{n_{21}}{m}-\frac{n_{22}}{m} \ln \frac{n_{22}}{m}$,

where $n_{11}$ is $S_{i}$, which belongs to the first category of $N_{I}$, and $S_{j}$ belongs to the first category of $N_{j}$, and so on.

2.3. Basic Principles of Building the Enterprise Information Resource Management Model Based on e-Commerce. In the daily management of an enterprise, the management level of an enterprise mainly depends on its organizational status [16]. A company with a good organizational level will have a benign development; otherwise, it will cause a vicious circle [17]. This is also determined by the organization's status [18]. Enterprise management gets rid of the subjective and arbitrary management stage, and the basic requirement for realizing e-commerce is to be more procedural and scientific [19]. The organizational environment will become more complex and changeable with the development of e-commerce. Therefore, the management level of enterprises has an important impact on the development of e-commerce. The following principles should be followed in the construction of enterprise information resource management mode based on e-commerce:

(1) The principle of good faith is that business managers should recognize that the management object is an organic whole of rules composed of several parts. It requires all market participants to obtain benefits without harming the interests of others and social welfare. It must also follow the rules of business managers. See established rules in [20]. Business management is a comprehensive project. We must consider the integration of production, supply, and marketing and fully consider the internal network environment of the enterprise, in order to get the appropriate management mode.

(2) The historical principle is one of the principles that have been followed from ancient times to the present [21]. When constructing the historical principle, we must consider the original system, the halfway development process, and the future development 
trend, so that the actual operation can be carried out well, and the development of the new model can also follow the changing trend of the times. It can be roughly carried out using historical principles and understood according to the laws of the original system in the process of formation and development, so as to prepare for the future development of the system [22].

(3) The principle of sharing is to share data in accordance with specific application scenarios. It can give full play to the potential value of corporate information and maximize corporate information management. Sharing under the new model can realize the use of information in different systems as a whole [23]. On the other hand, we must pay attention to the security of information sharing.

(4) The security principle is that the information must not be leaked in the enterprise, and the information security of the enterprise has always been the most concerned issue of all parties. Therefore, when constructing a new model [24], the security of enterprise information must be considered. This is also a key part of the entire system and is the basis and guarantee for subsequent development [25].

\subsection{Construction of the Enterprise Information Resource} Management Model Based on e-Commerce. The realization of e-commerce needs the support of a powerful e-commerce system. A perfect e-commerce system includes two parts: front end and back end. The front-end system is mainly a trading system for customer groups and suppliers, including accepting customer orders, sending orders to suppliers, and realizing online transactions and payments. The back-end system mainly realizes the information flow of enterprise sales and purchase. Manage business process, logistics, and capital flow effectively and timely. The backstage system mainly relies on the construction of internal information system. At present, some enterprises have created the e-commerce mode, but without the inventory information, production information, purchase information, transportation information, and customer information provided by the background information system; the front e-commerce platform cannot obtain relevant information. Secondly, it cannot deal with the market information in time and effectively, which leads to the disconnection between the front desk and the back office, the decrease of customer satisfaction, and the loss of customer base. It can be seen that enterprise informatization should be the premise of establishing e-commerce. Only by realizing the comprehensive informatization can enterprises develop e-commerce more effectively. Enterprises can establish the foreground system of e-commerce and the background system of internal supply chain management including sales and purchase. Through the coordination and control of the front and back offices, the effective management of the enterprise and the rational allocation and utilization of resources are realized. On this basis, the innovation of enterprise information resource management mode based on e-commerce is further realized. With the development of the Internet from a scientific network to a platform for business activities, the business activities of enterprises have broken through the limitation of time and space and changed the business activities and the way of value creation of enterprises. Therefore, based on the integration of the three systems, the application of e-commerce system must be increased. Through the e-commerce platform, the relationship between enterprises and customers can be extended to the whole network. Starting from meeting the key customers and appropriate customer needs, relying on the automatic management system, the comprehensive optimization of information flow, and logistics can be realized. Optimize the service flow and capital flow of each node enterprise and the enterprise, so as to realize the rapid development of the enterprise.

As shown in Figure 1, e-commerce provides a faster channel and platform for enterprises to obtain information. ERP is the basis of internal operation and management of the system enterprise. Supply chain management provides a fast and flexible supply chain for enterprises. CRM helps enterprises realize the marketing mode of personalized service. The four are interrelated and influence each other. e-Commerce can solve the space-time problem of information transmission. ERP emphasizes the optimization of internal resources. It takes internal supply chain management as the core. Supply chain management is an effective management of all aspects of the supply chain. It enables the supply chain to cross departments, cross enterprises, and form a business process with products or services as the core. Considering supply chain management from the perspective of the whole society, we can improve the competitiveness of all enterprises in the supply chain and make enterprises move towards cooperative competition. The value of CRM lies in highlighting the importance of customer service and support, marketing management and other aspects from the perspective of improving customer relationship, and improving the competitiveness and profits of enterprises in the Internet environment, as shown in Table 1.

From the perspective of enterprise information security, in the integrated management model of enterprise information system, three networks should be constructed first.

The first layer is the intranet. The purpose of Intranet construction is to help the production department, sales department, financial department, and human resource department communicate more conveniently and reliably, cooperate with each other in purchasing, marketing, assessment, and other work, and use intranet to realize the information data sharing of ERP, SCM, and CRM. Internal information resources are mainly accessed and shared by employees in the intranet to promote department collaboration. As the basis of the implementation of enterprise information resource strategy, this level can improve the basic operation efficiency of enterprises, greatly reduce the economic cost of various functional departments in enterprise activities, and increase output.

The second layer is the enterprise external network. Enterprise extranet is mainly aimed at the suppliers, distributors, and logistics distribution centers in the supply chain to realize the efficient operation of information flow, 


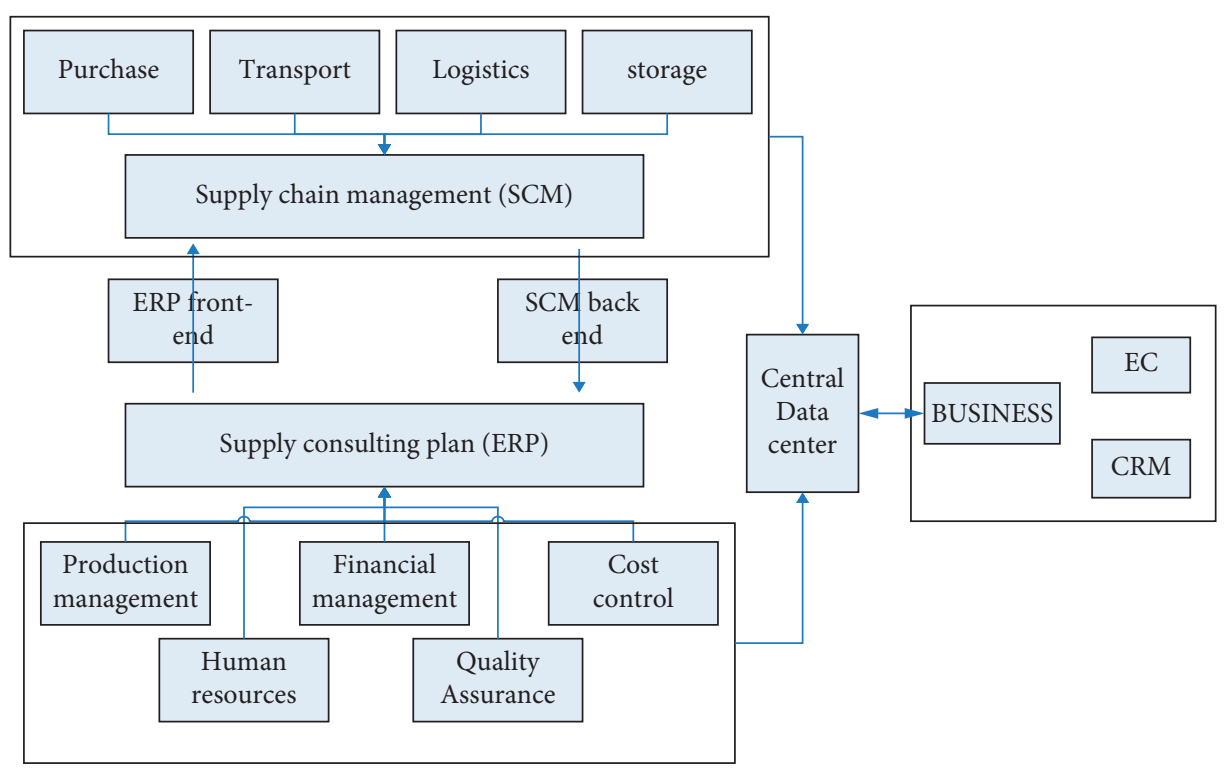

FIGURE 1: Enterprise information resource management model based on e-commerce.

TABLE 1: Difference comparison of ERP, CRM, and SCM.

\begin{tabular}{|c|c|c|}
\hline EAS & Management content & Key issues of implementation \\
\hline ERP & $\begin{array}{l}\text { Production plan, material requirement plan, purchase plan, } \\
\text { sales plan, utility plan, financial cost control plan, and human } \\
\text { resource plan. }\end{array}$ & $\begin{array}{l}\text { The key to solve this problem is to integrate and optimize the } \\
\text { resources within the enterprise. The idea of implementing supply } \\
\text { chain management in the enterprise reduces the cost from the } \\
\text { aspect of enterprise production process and improves the } \\
\text { competitiveness and profit of the enterprise. }\end{array}$ \\
\hline CRM & $\begin{array}{l}\text { Customer centered, including basic functions such as sales, } \\
\text { marketing and customer service support, focusing on the } \\
\text { effective exploration and utilization of customer resources by } \\
\text { enterprises. }\end{array}$ & $\begin{array}{l}\text { Focusing on increasing customer value, it can effectively meet the } \\
\text { personalized needs of customers, increase sales from the aspect of } \\
\text { customer relationship, and improve the response speed and } \\
\text { sensitivity of enterprises to the market and customers. }\end{array}$ \\
\hline SCM & $\begin{array}{l}\text { Coordinate with external resource integration and business to } \\
\text { realize the management of the whole supply chain. }\end{array}$ & $\begin{array}{l}\text { Taking customer satisfaction as the management goal, with the } \\
\text { help of information technology, making rapid response to market } \\
\text { demand, and ultimately improving the overall competitiveness of } \\
\text { the supply chain. }\end{array}$ \\
\hline
\end{tabular}

capital flow and logistics between the production enterprises and the final consumers. The enterprise terminal provides external interface and external network, and the interface is connected with the internal network to form a cooperative network system among partners. All business activities of the enterprise are carried out on the Internet, including online consultation, product ordering, product bargaining, and payment transaction. The real-time control of information improves the control of the enterprise, reduces the cost in the process of business activities, and achieves the purpose of reducing inventory. The integration and cooperation of enterprises in the supply chain has greatly improved the competitive advantage of enterprises in the industry.

The third layer is the Internet-based enterprise e-commerce network. It is supported by Internet technology, directly connected with the Internet, through e-commerce operation enterprise network, involving product sales and user service business network. In e-commerce network, enterprises use online mode to provide sales services for customers. At the same time, they can collect a large number of customer registration information and establish a special user recommendation system to gain competitive advantage. In addition, government agencies, banking institutions, and other social organizations should be included in the e-commerce network to provide policy and means support for online business activities of enterprises. The foundation of e-commerce is the establishment of information society. Therefore, the interaction between enterprises and social organizations can improve the utilization rate of social resources and promote the progress of the whole social economy.

The internal and external network construction is to solve the need of enterprise information confidentiality. Enterprises can exchange and share information with the outside world through e-commerce platform, including suppliers and customers. Suppliers or customers are not allowed to learn the internal information related to enterprise operation without authorization. The internal information of an enterprise is mainly the internal information obtained through the internal network. Exchange of 
interests. On the one hand, the construction of three-layer network can ensure the external security of enterprise information; on the other hand, it can realize the internal information sharing.

Enterprise information resource sharing is the key to an enterprise. It refers to the full discovery, mining, processing, and integration of information obtained in the internal and external environments of the enterprise, and the use of information to optimize the allocation of enterprise resources to realize its specific value and to improve production and operation to a certain extent. Efficiency can also promote a virtuous circle of enterprises. Because the enterprise is in a crisscross network environment, while sharing information, it may cause the leakage of business secrets and reduce the core competitiveness of the enterprise. Therefore, the contradiction between ensuring the internal information security of enterprises and realizing the information sharing among enterprises is the problem faced by the development of enterprises.

\section{Experiments}

3.1. Experimental Data Collection. Based on the establishment of a new model of enterprise information resource management, this paper conducts a simulation test on the specific information resource management. In the experiment, the method of simulating the information resource management environment was used to investigate the IT investment product structure of e-commerce companies from 2017 to 2019 , and the test results were counted. It was found that the product structure was gradually improved during a few years, and various indicators also increased. Quickly, the new model proposed in this paper can be well verified. In the research process, this paper uses case enterprise information resource management related information resources to collect through the crawler program.

3.2. Experimental Simulation. The case enterprise covers an area of square meters, including a construction area of square meters. There are 1 million yuan of existing assets, including 1 million yuan of fixed assets. At present, the company has more than employees, college degree or above, and professional and technical personnel including senior title personnel and intermediate title personnel. Each business unit focuses on profit, develops, produces, sells, and serves related products, and is responsible for profit and group investment. The headquarters operate in a unified way in investment decision-making, strategic planning, capital operation, and supervision.

3.3. Case Enterprise Structure. In the supply chain system, enterprises can be divided into three levels: core level enterprises, close level enterprises, and loose level enterprises. The core level enterprises are mainly to formulate enterprise strategic planning and coordinate the relationship with upstream and downstream partners. Close layer enterprises are the close partner enterprises of enterprises, which reflect the common competitiveness of the supply chain, mainly involving the key technologies that have a greater impact on enterprises, but the number of close layer enterprises should be moderate. Loose layer enterprises have great mobility, involving general technology and product outsourcing, and its loss will not cause a big blow to enterprises. The three-tier architecture of enterprise information resource management is shown in Figure 2.

\section{Discussion}

4.1. IT Investment Product Structure of e-Commerce Enterprises. According to the IT investment product structure survey of e-commerce enterprises in 2017-2019, as shown in Figure 3, the hardware investment is 63.54 billion yuan, accounting for $67.2 \%$ of the total IT investment. The total software investment of e-commerce enterprises is 18.34 billion yuan, accounting for $19.4 \%$ of the Department's IT investment. The total information service investment is 12.67 billion yuan, accounting for $13.4 \%$ of the Department's IT investment.

Compared with 2018, the investment in hardware products of e-commerce enterprises decreased by $3.3 \%$ in 2019 , and the proportion of software and information services increased by $2 \%$ and $1.3 \%$, respectively. With the maturity of IT service market, the demand of e-commerce enterprises for services has greatly increased. Outsourcing services (ASP) and IT consulting services are gradually accepted by more and more customers.

4.2. Analysis of the Enterprise Information Resource Management Model Based on e-Commerce. Enterprise information resource sharing based on the internal network of the enterprise includes information interaction between employees, functional departments, and other related organizations. However, the realization of enterprise information resource sharing within the enterprise is often limited by the enterprise software and hardware environment, which will cause information exchange between enterprises. Among them, the hard environment refers to the organizational structure of the enterprise, while the centralized management adopts the traditional pyramid organizational structure, which is not conducive to the smooth transmission of enterprise information and seriously reduces the sharing efficiency of internal information; the soft environment refers to the organizational culture of the enterprise, and the key to promote the innovation of knowledge management is whether the enterprise has the incentive trust association of employees.

Information resource sharing involves data exchange, authorized access, system research and development, system maintenance, e-commerce, and other fields. Data exchange technology is the main support for enterprises to realize information sharing. At present, there are two common ways of data exchange in enterprises: centralized and distributed.

As shown in Figure 4, intranet-based enterprises adopt centralized data exchange. In the establishment of a shared database in an enterprise, internal information resources can 


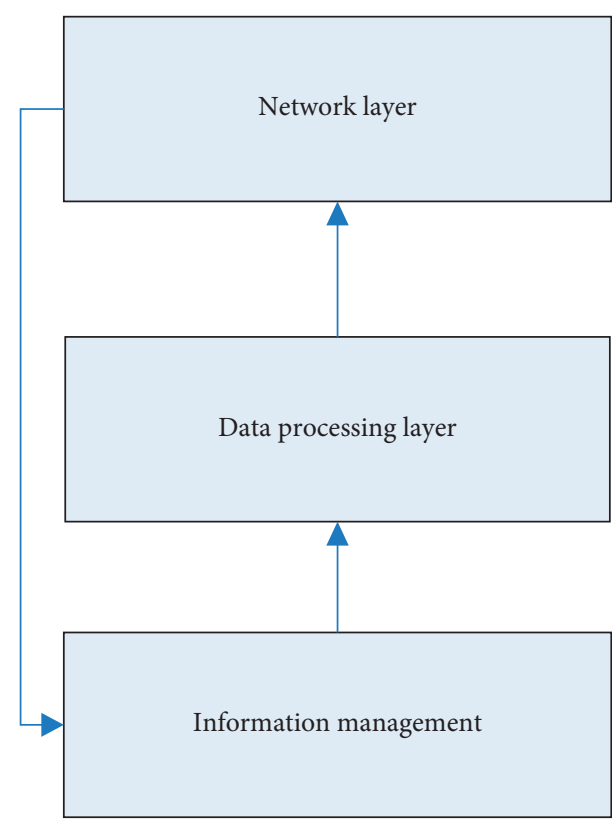

FIGURE 2: Three-layer architecture of enterprise information resource management.

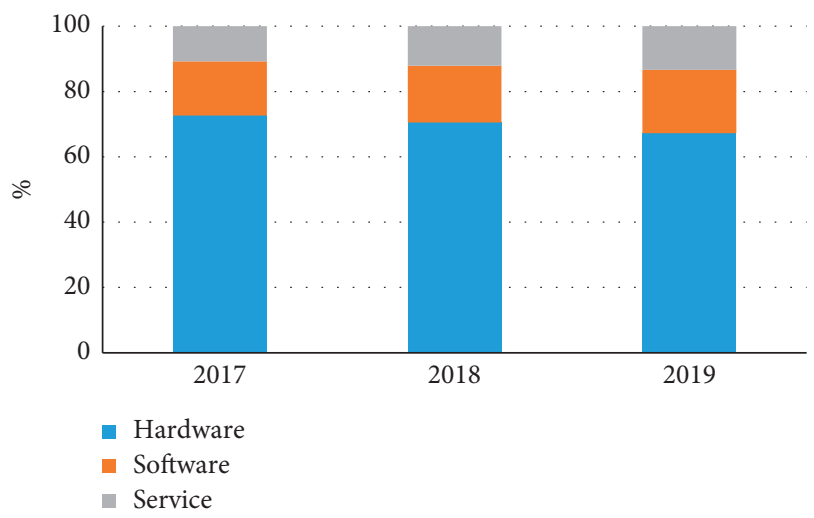

FIGURE 3: IT investment product structure of e-commerce enterprises.

be stored in the database for internal personnel to access and query data. Among them, centralized data exchange is widely used. The advantages of centralized data exchange include high access efficiency, centralized management, complete data, consistent structure standards, and strong real-time performance. The disadvantages of centralized data exchange are as follows: it cannot meet the requirements of the rapid growth of data volume brought about by the future development of enterprises.

Intranet-based enterprise information resources are distributed in different business databases. Distributed data exchange can transfer information resources between enterprises through exchange nodes. It not only creates conditions for real-time information exchange, remote access, and scale expansion but also helps enterprises reduce the risk of system implementation. But its disadvantage is that the efficiency of network transmission will affect the efficiency of data access and exchange, as shown in Figure 5.
4.2.1. Enterprise Information Resource Sharing Based on Extranet. The reason that affects the realization of enterprise information resource sharing based on extranet is that the relevant technology level is not up to the requirements, or the integrity of resource visitors is low. In the past, because of the low information transfer rate and the easy distortion of information, enterprises often made wrong production and inventory plans. In order to eliminate these negative effects, the concept of information resource sharing in supply chain came into being. The improvement of enterprise production efficiency, operation speed, and knowledge innovation all depend on the sharing of enterprise information resources based on extranet. In the supply chain, the key to realize knowledge innovation lies in the integration of knowledge among enterprises, the promotion of information sharing, the optimization of resource allocation, the continuous innovation, and the minimization of production cost, so as to enhance the common competitive advantage of enterprises and realize the maximization of enterprises. The common interests of chain enterprises are as follows. Of course, information resource sharing based on the Internet inevitably brings information security risks. If the enterprises in the chain violate the principle of cooperation and trust, the sharing of enterprise information resources will not continue.

A hybrid data exchange method is used in the enterprise, which combines the advantages of both centralized data exchange and distributed data exchange. The advantages of centralized data exchange and access are high in efficiency and real time, and distributed data exchange reduces risks and remote access. Using the combination of two methods to realize the sharing of information resources based on the external network, its core lies in data storage according to the importance of information. Information with high degree of sharing and strong openness can be stored in a centralized way, and core business data with strong independence can be stored in a decentralized way. It can not only access and exchange the data in the shared database but also provide direct access and exchange access through the central node as shown in Figure 6.

\subsubsection{Enterprise Information Resource Sharing Based on} Internet. The core information of enterprises is usually protected by strict security measures, while the core technology and professional knowledge are regarded as business secrets of enterprises. The correct strategic planning of an enterprise depends on the real-time exchange of safe and reliable information. On the Internet, different enterprises have different information systems, different structures, and different exchange requirements. Therefore, the Internetbased enterprise information resource sharing should adopt the central exchange node and comprehensive mixed data exchange mode. The internal information demander exchanges data with the department database through the exchange subnodes of each business unit and then through the central exchange node of the cooperative enterprise. The department database uploads the relevant information to the supply chain enterprise central database to realize the core 


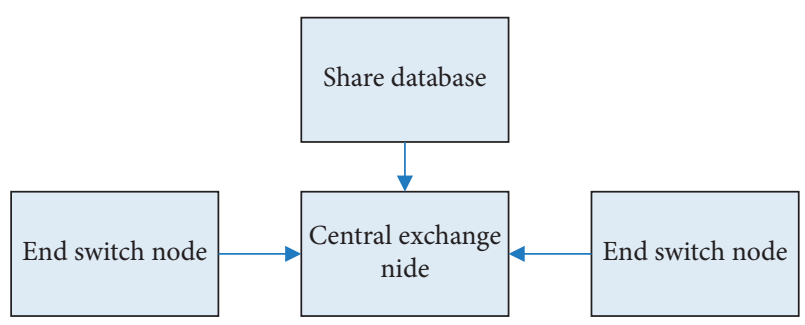

FIgURE 4: Centralized data exchange.

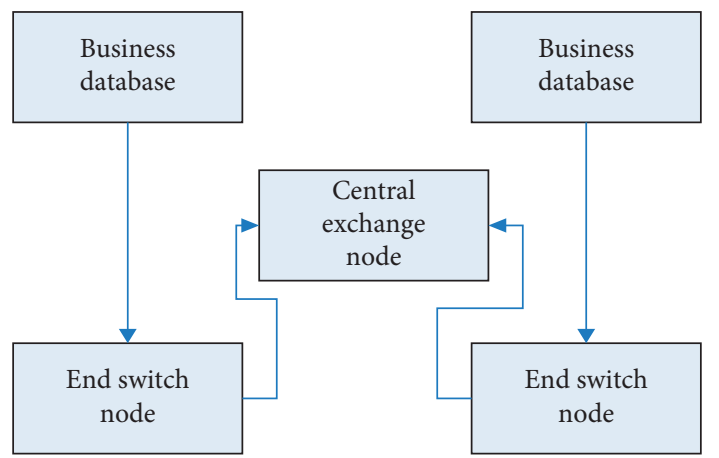

FIgURE 5: Distributed data exchange.

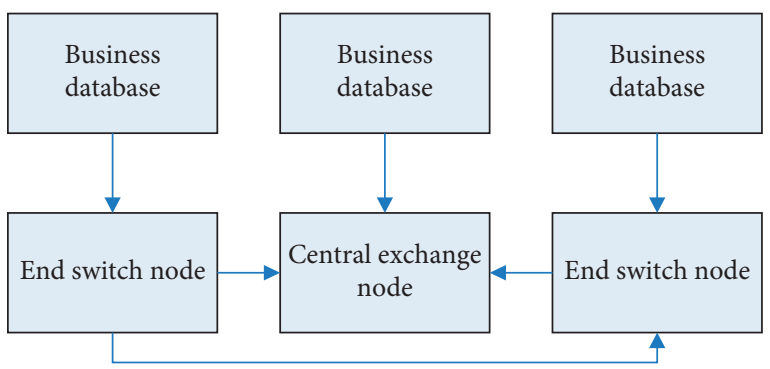

FIgure 6: Hybrid data exchange.

information sharing. The external information demander can only access the central database sharing through its own subnode public basic information resources. The child node can directly access the other's child nodes through the central node, so as to obtain some information that is not convenient to be widely disclosed in the central database. The information resources of public basic enterprises are stored in the central database. For some information resources that need to be kept secret, personal management should be implemented accordingly, and the way of personal subnode exchange through the central node should be adopted. The mixed data exchange mode can provide information monitoring, record exchange logs, and other functions, which can help to deal with failures, solve postevent responsibility identification and other issues, and promote the improvement of social supervision mechanism.

\section{Conclusions}

At present, enterprise information resource management in e-commerce environment has become one of the key and hot issues in the field of information resource management.
As an important branch of information resource management, the research of enterprise three-dimensional information resource management mode in e-commerce environment has not shown any special literature, let alone the review and summary of existing research. Especially in information resource management, Internet/intranet/ extranet technology, e-commerce, and other fields, there is a lack of comprehensive integration. The first part of this paper mainly introduces the purpose and significance of this study, makes a brief review of the research status of enterprise information resource management, and briefly describes the research content and main work of this paper.

Based on the research of some information resource management projects and tutor projects in China, combined with the theories of information resource management, e-commerce, and management information system, and based on Internet, intranet, and extranet technologies, this paper proposes a new information resource management method: ERP (enterprise resource planning), SCM (supply chain management), and CRM (customer management). Relationship Management). Based on the three-dimensional information resource management model, the system combines information resource management with e-commerce. It not only deals with the business of customers and suppliers but also manages the internal resource information in real time. It realizes the information sharing of heterogeneous systems, effectively eliminates the information island, conveniently optimizes the allocation of information resources, and overcomes the problems of various departments. The information failure and asymmetry between enterprises reflect a kind of management idea of horizontal and vertical integration.

This paper studies the three-dimensional information resource management model of enterprises in e-commerce environment. This paper first introduces the purpose and significance of this study, briefly reviews the research status of enterprise information resource management at home and abroad, and summarizes the existing research results. At the same time, this part also briefly introduces the research content and innovation of this paper. Then, it analyzes the enterprise information resource management in the e-commerce environment; on this basis, it puts forward the enterprise three-dimensional information resource management idea of "three networks" + "three systems" and gives the definition of enterprise three-dimensional information resource management. In addition, this paper also analyzes the three-dimensional information resource management platform Internet, intranet, extranet, and the management network of ERP, SCM, and CRM systems, and analyzes the differences between them from the management content and implementation key issues. Secondly, the framework of enterprise 3D information resource management model is studied, the function structure and architecture of enterprise 3D information resource management model are proposed, and the model is analyzed. Finally, it discusses the construction of enterprise 3D information resource management model, introduces the integration scheme of Web services from the aspect of technology realization, and puts forward the design idea of 
enterprise 3D information resource management model. This paper constructs a three-dimensional information resource management model based on J2EE system in e-commerce environment.

\section{Data Availability}

No data were used to support this study.

\section{Conflicts of Interest}

The authors declare that they have no conflicts of interest.

\section{Acknowledgments}

This work was supported by the major project of Beijing Social Science Foundation "Research on Financial Support System Adapting to the Coordinated Development of Strategic Emerging Industries in Beijing-Tianjin-Hebei," under no. 20ZDA11.

\section{References}

[1] S. Fang, Y. Zhu, L. Xu et al., "An integrated system for land resources supervision based on the IoT and cloud computing," Enterprise Information Systems, vol. 11, no. 1, pp. 1-17, 2015.

[2] L. M. Mohamed, "Exploring the critical success factors (CSF) and limitations of enterprise resource planning (ERP) systems: the case of Egyptian hotels," Journal of Hospitality Management \& Tourism, vol. 6, no. 3, pp. 17-29, 2015.

[3] N. Evans and J. Price, "Enterprise information asset management: the roles and responsibilities of executive boards," Knowledge Management Research \& Practice, vol. 14, no. 3, pp. 353-361, 2016.

[4] J. Filipe, "Enterprise information systems," Lecture Notes in Business Information Processing, vol. 109, no. 6, pp. 147-157, 2015.

[5] G. Poels, "Enterprise information systems of the future," Lecture Notes in Business Information Processing, vol. 9, no. 4, pp. 2147-2154, 2017.

[6] J. Xu, C. Liu, X. Zhao, S. Yongchareon, and Z. Ding, "Resource management for business process scheduling in the presence of availability constraints," ACM Transactions on Management Information Systems, vol. 7, no. 3, p. 9, 2016.

[7] R. G. Saade and H. Nijher, "Critical success factors in enterprise resource planning implementation," Journal of Enterprise Information Management, vol. 29, no. 1, pp. 72-96, 2016.

[8] S. Frank, C. Fürst, and F. Pietzsch, "Cross-sectoral resource management: how forest management alternatives affect the provision of biomass and other ecosystem services," Journal of Forests, vol. 6, no. 3, pp. 533-560, 2015.

[9] G. Tang and H. U. Liang, "A medical devices management information system supporting full life-cycle process management," Zhongguo Yi Liao Qi Xie Za Zhi, vol. 39, no. 4, pp. 304-306, 2015.

[10] S. Abels, N. Brehm, A. Hahn, and J. M. Gomez, "Change management issues in Federated ERP systems: an approach for identifying requirements and possible solutions," International Journal of Information Systems \& Change Management, vol. 1, no. 3, pp. 318-335, 2017.

[11] P. Wang and W. Han, "Construction of a new financial E-commerce model for small and medium-sized enterprise financing based on multiple linear logistic regression," Journal of Organizational and End User Computing, vol. 33, no. 6, 2021.

[12] B. Link and A. Back, "Classifying systemic differences between software as a service- and on-premise-enterprise resource planning," Journal of Enterprise Information Management, vol. 28 , no. 6, pp. 808-837, 2015.

[13] R. Seethamraju, "Adoption of software as a service (SaaS) enterprise resource planning (ERP) systems in small and medium sized enterprises (SMEs)," Information Systems Frontiers, vol. 17, no. 3, pp. 475-492, 2015.

[14] Z. D. Zhou, R. Valerdi, and S. M. Zhou, "Guest editorial special section on enterprise systems," IEEE Transactions on Industrial Informatics, vol. 8, no. 3, p. 630, 2015.

[15] L. Li and J. Zhang, "Research and analysis of an enterprise E-commerce marketing system under the big data environment," Journal of Organizational and End User Computing, vol. 33, no. 6, 2021.

[16] H. A. Reijers, I. Vanderfeesten, and W. M. P. Van Der Aalst, "The effectiveness of workflow management systems: a longitudinal study," International Journal of Information Management, vol. 36, no. 1, pp. 126-141, 2016.

[17] D. Sedera, S. Lokuge, V. Grover, S. Sarker, and S. Sarker, "Innovating with enterprise systems and digital platforms: a contingent resource-based theory view," Information \& Management, vol. 53, no. 3, pp. 366-379, 2016.

[18] G. He, "Enterprise E-commerce marketing system based on big data methods of maintaining social relations in the process of E-commerce environmental commodity," Journal of Organizational and End User Computing, vol. 33, no. 6, 2021.

[19] J. Martínez-Ferrero, S. Banerjee, and I. M. García-Sánchez, "Corporate social responsibility as a strategic shield against costs of earnings management practices," Journal of Business Ethics, vol. 133, no. 2, pp. 305-324, 2016.

[20] S.-B. Tsai, "Using the DEMATEL model to explore the job satisfaction of research and development professionals in China's photovoltaic cell industry," Renewable and Sustainable Energy Reviews, vol. 81, pp. 62-68, 2018.

[21] S.-B. Tsai, C.-Y. Huang, C.-K. Wang et al., "Using a mixed model to evaluate job satisfaction in high-tech industries," PLoS One, vol. 11, no. 5, Article ID e0154071, 2016.

[22] K. Lu, J. Zhu, and H. Bao, "High-performance human resource management and firm performance," Industrial Management \& Data Systems, vol. 115, no. 2, pp. 353-382, 2015.

[23] X. Jie and J. Zhuang, "Modeling costly learning and counterlearning in a defender-attacker game with private defender information," Annals of Operations Research, vol. 236, no. 1, pp. 271-289, 2016.

[24] C. E. H. Chua and V. C. Storey, "Bottom-up enterprise information systems," Communications of the ACM, vol. 60, no. 1, pp. 66-72, 2016.

[25] K. Lyytinen and M. Newman, "A tale of two coalitionsmarginalising the users while successfully implementing an enterprise resource planning system," Information Systems Journal, vol. 25, no. 2, pp. 71-101, 2015. 